\title{
Re-examination and expanding the EUCS Model on Cloud- based ERP system
}

\author{
Weli Weli \\ Faculty of Economics and Business \\ Atma Jaya Catholic University of Indonesia, Jakarta
}

weli.imbiri@atmajaya.ac.id

\begin{abstract}
The end-user computing satisfaction model (EUCS) has been widely used in previous studies, and Enterprise Resource Planning. Therefore, Enterprise Resource Planning (ERP) System, need to be developed in accordance with cloud computing that dominate current information technology devices. This study was carried out to test the expansion of the EUCS model in a cloud-based ERP system. Therefore, the purpose of this research is to re-examine the validity and reliability of the computer application satisfaction model and its relationship with user performance in cloud-based ERP system. The overall satisfaction variable is added as a mediation between the satisfaction model and user performance. Data was collected through snowball sampling with a questionnaire distributed to the cloud-based ERP users. Additionally, data processing was conducted using the Second-order concept in structural equation modeling with the Partial Least Square approach. Since data processing using WarpPLS confirmed the validity and reliability of the model and all relationships between variables, this research contributes theoretically to the study of end-user satisfaction from information technology applications. Its final section describes the limitations and opportunities for future research.
\end{abstract}

Keywords: ERP, Cloud-based, EUCS, end-user satisfaction, performance

\section{Introduction}

The end-user computing satisfaction (EUCS) was initially developed to measure the satisfaction level of end-user computers in the early 1980s. EUCS is a measurement of affective attitudes towards specific computer-based applications by someone directly interacting with the applications [1].According to the EUCS concept, user satisfaction is measured based on the perception of content, accuracy, format, ease of use, and timeliness. With these 5 dimensions, satisfaction shows the excellent quality and acceptance level of the system application used. Until now, EUCS has been widely applied in various types of computer internet-based applications studies, including the ERP application.

Previous studies have shown adequate consistency and validity in measuring the satisfaction of end-user information systems [1]-[7]. Previous research showed that the EUCS instrument is consistent in measuring user satisfaction for conventional 
ERP systems [6]. ERP users are delighted with the system's accuracy, and they provide the highest rank for the timeliness. The ease of use and user-friendliness was ranked the lowest. The psychometric properties of EUCS appear strong in all studies and user groups. However, some studies stated that EUCS could not be used as a final model in explaining the end-user satisfaction of computer applications [6], [7]. Furthermore, research suggested to improve by re-validating and extending the EUCS Model [6]. Subsequently, this study validates the EUCS model concerning cloudbased Enterprise Resource Planning (ERP) users.

According to Zhong \& Rhode [8], cloud-based ERP applications is a new domain, with little research conducted on their adoption. The EUCS instrument has not been validated on ERP cloud. This research examines the ERP application and its relation to the computing domain separately. The prospects for future developments that allow migration from conventional to cloud-based ERP, the EUCS model is reevaluated on cloud-based ERP users.

Cloud-based ERP testing was performed because there is much anecdotal evidence pointing to its benefits, especially in organizations. For instance, there is increased efficiency with high application scalability, lower hardware costs, information integration, and faster response time to customers. This leads to improved customer satisfaction and company image [9].

ERP is an interesting research topic, though its implementation is expensive[10], [11]. However, the factors of globalization, centralization, and performance improvement make large and small-scale companies implement ERP [12]. Reports from several application supervisors support the increase in the number of companies investing in the ERP sector. For instance, Oracle claims that there has been a massive investment in cloud-based ERP systems. This is in line with the report from the global ERP Software Market, published by KBV Research in 2019[13]. The report predicts a substantial increase in the ERP market in 2025. Therefore, it is challenging to assess the benefits of this substantial investment. The challenge is whether a substantial investment in implementing the ERP application is beneficial to the company in terms of value.

\subsection{End-User Satisfaction Model in ERP Systems}

The concept of user satisfaction was initially intended to assess the success of information system implementation. Satisfaction is closely related to the success of the system in fulfilling user needs [2], [14]. Furthermore, user satisfaction shows whether the implemented system is effective [1]. Overall individual satisfaction towards information systems is evaluated cognitively. Measurements should be conducted to determine whether the system has fulfilled user needs. Based on the overall satisfaction, this study adopts the concept proposed in [1]. It expands the EUCS model towards overall user satisfaction. This variable serves as a mediation between the EUCS model and individual performance in using ERP cloud system, especially SaaS with Oracle vendors.

The relationship between user satisfaction and individual performance is based on interaction with the system. Previous research focused on ERP impact at the 
organizational level, with very few examinations on how it influences individual users [15]. When the use of an ERP system is beneficial to the organization, the end-users also indirectly benefit from using it. This is possible because the end-user always interacts with the system. Furthermore, when the end-users feel the benefits, their productivity positively affects the organization. Therefore, successful implementation of the system should be measured based on user satisfaction. The study confirmed the relationship between satisfaction and individual performance in using ERP systems [8]. This was supported by similar studies in various application groups, such as elearning [16], customer information systems [17], e-government systems [18], and mbanking [19].

Based on the description above, this study confirms and extends the End User Computing Satisfaction (EUCS) model. Confirmation is conducted in the domain of cloud-based ERP systems, especially for SaaS with Oracle vendors. Furthermore, the satisfaction model is related to end-user performance [8], [9], [12], [15], [17]. Based on the model developed, expansion is conducted by adding the overall satisfaction variable [1]. Although the EUCS model has been widely used in various studies with different information system applications, this research contributes to cloud-based ERP systems. Furthermore, the user satisfaction instrument is tested with the secondorder variable concept.

\subsection{Research Model}

The research model predicts that a higher user satisfaction level of ERP cloud system increases performance, as shown in Figure 1. The user satisfaction model is based on the ease of use, content, timeliness, accuracy, and format. Furthermore, the model is extended towards overall satisfaction and related to individual performance. Hence, it follows the concept of the ERP User Satisfaction as the second-order latent variable. The indicators of this variable are ease of use, content, timeliness, accuracy, and format, which is the first-order latent variable.

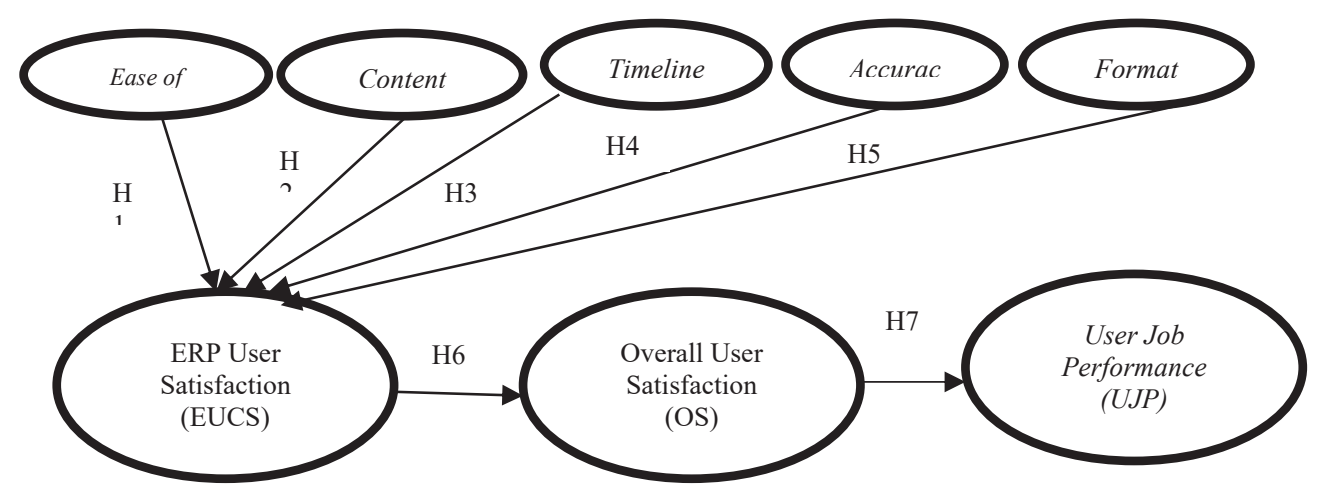

Figure 1 The Research Model 
Based on the EUCS concept designed by Doll \& Torkzadeh [20], user satisfaction is defined as the extent to which application users believe that the available system meets their requirements. The user satisfaction component is their interaction experience when using the application. This is reflected in the affective attitude of satisfaction towards measurable applications through 5 dimensions, namely 1) ease of use that reflects user-friendliness, 2) content that meets user expectations, 3) timeliness of information presentation, 4) accuracy of the information and 5) presentation format of information under user expectations, [5]

The previous studies results [1], [2], [6], [7] provide empirical evidence and confirmation of the 5 dimensions that establish EUCS. Ease of use is a subjective perception by users. It reflects user-friendliness [6] in browsing, finding, and editing content provided by the system [17]. An easy-to-use system provides satisfaction to users because they do not experience operational problems. Furthermore, the easier the access to the system, the more users feel the benefits.

Similarly, the good content design tends to generate useful information for its users and increase their trust [21][17]. Information content that meets user expectations impacts on their satisfaction ability to carry out their job. The more appropriate the content presented by the application, the better the response given by the user.

This is not less important than other dimensions, whereby the timeliness and accuracy of presenting information also play an important role in determining system user satisfaction because it is related to their accuracy in solving problems [1]-[3]. Inaccurate information leads to errors in the decision-making process, with the format defined as the presentation of information in a form that matches user expectations. Application users can use the system, browse the site, find and edit content according to an information presentation format and help others understand information clearly [21][17].

Furthermore, the relationship between end user satisfaction and individual performance is explained through the successful implementation of the system, which is described as the level of acceptance by users willing to voluntarily use it to meet their various needs [22]. Successful system implementation reflects on their acceptance, which is manifested from the level of use and increased individual performance [1], [5].

Therefore, based on the description above, the research hypothesis is formulated as follows:

H1: Ease of Use is a forming element in cloud ERP user satisfaction

$\mathrm{H} 2$ : Content is a forming element in cloud ERP user satisfaction

H3: Timeliness is a forming element in cloud ERP user satisfaction

H4: Accuracy is a forming element in cloud ERP user satisfaction

H5: Format is a forming element in cloud ERP user satisfaction

H6: ERP Cloud User Satisfaction is related to overall Satisfaction

$\mathrm{H7}$ : Overall satisfaction is related to user performance. 
The next section explains the research methods consisting of data collection, variable operationalization, and data processing methods. This is followed by the analysis section and discussion of the data processing results, as well as conclusions.

\section{Research Method}

The following diagram explains the approach used in this research

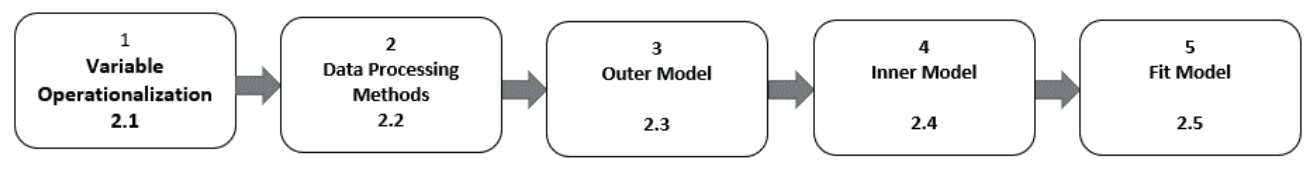

Figure 2. Research Method

This study used primary data by distributing questionnaires from October to November 2019. Respondents were end-users of the Cloud-based SaaS ERP system in Jakarta, especially with Oracle vendors. Data were collected using the snowball sampling technique with Google Form and sent via social media using Whatsapp, Line, or e-mail. The data collection obtained 100 responses. Furthermore, the questionnaire was compiled based on the EUCS model, which had been translated into Indonesian. It was modified by measuring the overall satisfaction of the research adoption results [1]. The modification of previous studies [8], [9], [12], [15], [17] was used to measure individual performance according to the use of ERP cloud system. The following sections describe each instrument.

\subsection{Variable Operationalization}

The following are the dimensions and constructs used in this study.

\section{End-User Computing Satisfaction (EUCS)}

Based on the measurement Doll and Torkzadeh model[20], EUCS is formed from the following 5 dimensions:

1. Ease of Use. This is the user satisfaction level due to interaction with the system easily understood without much effort. It is measured using following 5 questions:

- $\quad$ ERP cloud is easy to operate.

- The interaction with ERP cloud system is flexible.

- ERP cloud is easy to understand.

- There is no difficulty using ERP cloud.

- ERP cloud is user friendly.

2. Content. This is the extent to which the system output is available according to user needs, measured using 3 questions: 
- ERP cloud helps provide the right information/according to the requirements.

- ERP cloud displays the report as desired.

- ERP cloud helps generate accurate information.

3. Timeliness. This is how timely the information should be presented. It is measured using 3 questions:

- ERP cloud helps provide up to date information.

- ERP cloud supports the provision of information for a fast and precise time.

- ERP cloud helps to release report results on time.

4. Format. This is related to the application's appearance as presented and used by the user. This variable is measured using 3 questions:

- ERP cloud helps display output in a useful format.

- ERP cloud helps to present information more clearly.

- ERP cloud display formats are easy to understand.

5. Accuracy. Refers to the degree of correctness of the information presented by technology, measured using 3 questions:

- ERP cloud provides accurate information.

- ERP cloud helps display the appropriately presented output.

- ERP cloud helps reduce mis served in compiling reports.

Overall satisfaction (OS)

Overall satisfaction is an attitude towards the use of a cloud-based ERP system, measured using 6 questions:

- I am satisfied with the convenience provided by ERP cloud.

- I am satisfied with the content of ERP cloud.

- I am satisfied with the timeliness of information available in ERP cloud.

- I am satisfied with the format presented by ERP cloud.

- I am satisfied in using ERP cloud.

- Overall, I am satisfied in using ERP cloud.

\section{User Job Performance (UJP)}

This describes the user's performance achievement based on their experience in using a cloud ERP system. This variable is measured based on the IS Success Model with several adjustments:

- Using ERP cloud allows me to accomplish tasks faster.

- Using ERP cloud increases my productivity.

- Using ERP cloud improves the performance of my job.

- Using ERP cloud enables me to get more done.

- Using ERP cloud enhances the results of my job.

The indicators used in this study were measured using a 5-point Likert scale, where 1 represented strongly disagree and 5 strongly agree. A higher score indicated a high acceptance level for each statement. 


\subsection{Data Processing Methods}

Data were processed using the Structural Equation Model (SEM) method, with the Partial Least Square (PLS) or the Variance Based approach. The PLS method utilizes two interactive procedures that use least squares estimation for single and multicomponent models. PLS is a powerful analytical method because, with bootstrapping facilities, data is processed without considering assumption problems, such as multicollinearity, and normality. Moreover, data is processed with certain scale measurements, even with a small number of samples [18]. However, it is only used to predict models and assess the relationship between constructs [18]. The program used for data processing was WarpPLS 7.0, developed by Professor Ned Knock in 2010 [23].

In line with the PLS approach, the data were processed in stages consisting of:

1. Testing the research model with second-order latent variables by evaluating the measurement model (Outer Model).

2. Evaluating the structural model (Inner Model).

3. Testing the model fit (Model Fit).

\subsection{Evaluation of the Measurement Model (Outer Model)}

The measurement model was evaluated to determine the effect of indicators in explaining the latent variables. This test was performed in 3 stages, including [23]

1. Convergent Validity

Convergent validity was assessed by comparing the correlation between the indicator and construct (loading factor) values. When the loading factor value is greater than 0.5 , the indicator fulfills the Convergent Validity criteria.

2. Discriminant Validity

Discriminant Validity was assessed in 2 approaches. In the first approach, the cross-loading table between constructs was examined. When the correlation value of a construct in the same indicator is greater than other constructs, a latent construct predicts the indicator of each construct more than the other indicators. The second approach involved looking at the Average Variance Extracted (AVE) value, which should be greater than 0.5 .

3. Composite Reliability

It was assessed by looking at the Composite Reliability and Cronbach's Alpha value. When the value of a construct is greater than 0.7 , it fulfills the Composite Reliability criteria.

\subsection{Evaluation of Structural Model (Inner Model)}

The structural model was evaluated to test the significance of the relationship between the constructs. The evaluation was conducted in 3 stages [23], including:

1. Evaluation of the $\mathrm{R}^{2}$ value was used to measure the degree of variation change in the independent variable towards the dependent variable. The higher the $\mathrm{R}^{2}$ value, the better the prediction of the proposed research model. 
2. Evaluation of the path coefficient value was used to assess the relationship between constructs. It is conducted by looking at the path coefficient score indicated by the $\mathrm{p}$-value at $\mathrm{p}<0.05$.

3. Effect Size evaluation was performed to assess the effect of predictor latent variables from a practical perspective. When the value of the effect size is $>$ 0.35 , the variable has a strong influence, and for a value $<0.15$ has a moderate and weak effect when it is less than 0.02 .

\subsection{Evaluation of Fit Goodness Model}

At this stage, the assessment was performed by evaluating the suitability of the model towards the data collected. The evaluation was conducted using the fit index model provided in the output of WarpPLS version 7.0, as summarized in Table 1 [23].

\begin{tabular}{|l|l|}
\hline Indeks & Criteria \\
\hline Adjusted R & $\begin{array}{l}>=0.70 \Rightarrow \text { Strong, }>=0.45 \quad=> \\
\text { Moderate, }<=0.25=>\text { Weak }\end{array}$ \\
\hline Average Path Coefficient (APC) & $\mathrm{p}<0.05=>$ acceptable \\
\hline Average R-Squared (ARS) & $\mathrm{p}<0.05,=>$ acceptable \\
\hline Average Adjusted R-Squared (AARS) & $\mathrm{p}<0.05,=>$ acceptable \\
\hline Average Block VIF (AVIF) & $<=5=>$ acceptable, $<=3.3=>$ ideally \\
\hline Average Full Collinearity VIF (AFVIF) & $<=5=>$ acceptable, $<=3.3=>$ ideally \\
\hline Tenenhaus GoF (GoF) & $\begin{array}{l}>=0.1=>\text { small, }>=0.25=>\text { medium, } \\
>=0.36=>\text { large }\end{array}$ \\
\hline Sympson's Paradox ratio (SPR) & $>=0.70=>$ acceptable, $1==>$ ideally \\
\hline R-squared Contribution Ratio (RSCR) & $>0.90$, acceptable, $1=>$ ideally \\
\hline Statistical Suppression Ratio (SSR) & $>=0.70=>$ acceptable \\
\hline $\begin{array}{l}\text { Nonlinear Bivariate Causality Direction } \\
\text { Ratio (NLBCDR) }\end{array}$ & $>=0.70=>$ acceptable \\
\hline
\end{tabular}

Table 1. Model fit criteria

\section{Result}

General Description of Respondents and Research Variables

The information in Table 2. illustrates that most respondents were women below the age of 30, with undergraduate education. Furthermore, the majority of respondents had less than 3 years of work experience in Financial \& Accounting with staff positions. 


\begin{tabular}{|c|c|c|c|c|c|}
\hline Description & & Total & Description & & Total \\
\hline \multicolumn{3}{|l|}{ Age } & \multicolumn{3}{|l|}{ Department } \\
\hline$<30$ year & 66 & $66 \%$ & Sales \& Marketing & 16 & $16 \%$ \\
\hline $30-40$ year & 33 & $33 \%$ & Financial \& Accounting & 67 & $67 \%$ \\
\hline$>40$ year & 1 & $1 \%$ & Operating & 4 & $4 \%$ \\
\hline \multicolumn{3}{|l|}{ Gender } & Production & 3 & $3 \%$ \\
\hline Male & 26 & $26 \%$ & Supporting & 4 & $4 \%$ \\
\hline Female & 74 & $74 \%$ & Purchasing & 6 & $6 \%$ \\
\hline \multicolumn{3}{|l|}{ Experiences } & \multicolumn{3}{|l|}{ Position } \\
\hline$<1$ year & 14 & $14 \%$ & Supervisor & 8 & $8 \%$ \\
\hline $1-3$ year & 61 & $61 \%$ & Staff & 89 & $89 \%$ \\
\hline $3-5$ year & 16 & $16 \%$ & & & \\
\hline $5-10$ year & 6 & $6 \%$ & \multicolumn{3}{|l|}{ Education } \\
\hline$>10$ year & 3 & $3 \%$ & Undergraduate & 100 & $100 \%$ \\
\hline
\end{tabular}

Table 2. Characteristics of respondents

According to Table 3, characteristics of research variables describe the overall condition perceived as high, which is above 4 out of 5, except for ease of use, with a score of 3.64. This indicates a reasonably high satisfaction level for all variables. However, the items about ease of use on a cloud-based ERP system are still problematic.

\begin{tabular}{|l|c|c|}
\hline \multicolumn{1}{|c|}{ Variabel } & Total items & Mean \\
\hline Ease of Use & 5 & 3.64 \\
\hline Content & 3 & 4,20 \\
\hline Timeliness & 3 & 4.16 \\
\hline Accuracy & 3 & 4.18 \\
\hline Format & 3 & 4.15 \\
\hline Overall Satisfaction & 6 & 4.05 \\
\hline User Job Performance & 5 & 4.05 \\
\hline
\end{tabular}

Table 3. Characteristics of latent variables

\subsection{Measurement Model Evaluation (Outer Model) of First-Order}

Based on the first-stage evaluation results, all the first-order indicators forming the EUCS variable display the loading factor value greater than 0.7 , except for the AC3 indicator at 0.680 . However, this value is still useful because it is above 0.5 [23]. The values of Cronbach Alpha, Composite Reliability (CR), and Average Extracted 
Variance (AVE) are all greater than 0.7, as summarized in Table 4. Therefore, based on these results, all indicators have good convergent validity, and effectively explain latent variables.

The next evaluation assessed the discriminatory validity of the construction by looking at the cross-loading value. The values in Table 5. show that all indicators have a higher correlation on the latent variable than the other variables. This is evidenced by the Average Extracted Variance (AVE) score. From Table 4, all indicators have AVE values greater than 0.5 . Therefore, all indicators explain each latent variable well, as indicated by high correlation values. Subsequently, the First-order outer model was evaluated using composite reliability values and Cronbach's Alpha. As presented in Table 4, the values of the two measures for all latent variables show a score higher than 0.7 . Therefore, the constructs have high reliability.

The first-order model test results show that the cloud-based ERP user satisfaction measurement model has fulfilled the concepts of convergent validity, discriminant validity, and composite reliability. Therefore, the first-order of EUCS instrument used has good validity and reliability.

\begin{tabular}{|c|c|c|}
\hline \multicolumn{2}{|c|}{ Indicator/ Variable/ Items } & Loading Factors \\
\hline \multicolumn{3}{|c|}{ Ease of use $($ Cronbach Alpha $=0.929, \mathrm{CR}=0.947, \mathrm{AVE}=0.784)$} \\
\hline EOU1 & ERP cloud is easy to operate & 0.747 \\
\hline EOU2 & The interaction with the ERP cloud system is flexible & 0.919 \\
\hline EOU3 & ERP cloud is easy to understand & 0.907 \\
\hline EOU4 & There is no difficulty using ERP cloud & 0.921 \\
\hline EOU5 & ERP cloud is user friendly & 0.919 \\
\hline \multicolumn{3}{|c|}{ Content $($ Cronbach Alpha $=0.875, \mathrm{CR}=0.923, \mathrm{AVE}=0.800)$} \\
\hline CN1 & $\begin{array}{l}\text { ERP cloud helps provide the right information/according to the } \\
\text { requirements }\end{array}$ & 0.918 \\
\hline $\mathrm{CN} 2$ & ERP cloud displays the report as desired & 0.878 \\
\hline CN3 & ERP cloud helps generate accurate information & 0.887 \\
\hline \multicolumn{3}{|c|}{ Timeliness $($ Cronbach Alpha $=0.875, C R=0.923$, AVE $=0.800)$} \\
\hline TM1 & ERP cloud helps provide up to date information & 0.918 \\
\hline TM2 & $\begin{array}{l}\text { ERP cloud supports the provision of information for a fast and } \\
\text { precise time }\end{array}$ & 0.878 \\
\hline TM3 & ERP cloud helps to release report results on time & 0.887 \\
\hline \multicolumn{3}{|c|}{ Accuracy $($ Cronbach Alpha $=0.798, C R=0.884, \mathrm{AVE}=0.721)$} \\
\hline $\mathrm{AC} 1$ & ERP cloud provides accurate information & 0.923 \\
\hline $\mathrm{AC} 2$ & ERP cloud helps display the appropriately presented output & 0.921 \\
\hline $\mathrm{AC} 3$ & ERP cloud helps reduce misserved in compiling reports & 0.680 \\
\hline \multicolumn{3}{|c|}{ Format $($ Cronbach Alpha $=0.860, C R=0.916, A V E=0.784)$} \\
\hline
\end{tabular}




\begin{tabular}{|l|l|r|}
\hline FM1 & ERP cloud helps display output in a useful format & 0.915 \\
\hline FM2 & ERP cloud helps to present information more clearly & 0.936 \\
\hline FM3 & ERP cloud display formats are easy to understand & 0.799 \\
\hline
\end{tabular}

Table 4. Test result for first-order outer model
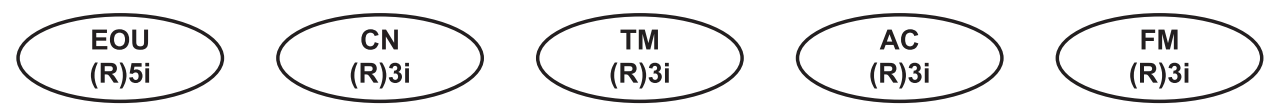

Figure 3. First-order laten variable

\subsection{Measurement Model Evaluation (outer model) of Second-Order}

After the first-order latent variables evaluation showing good validity and reliability, the second-order latent variables were tested. The summary results in Table 6 illustrates the acceptable values for all indicators because it has a loading factor greater than 0.7. Similarly, the Cronbach Alpha, Composite Reliability (CR), and Average Extracted Variance (AVE) values were greater than 0.7. Furthermore, the evaluation of discriminant validity, as seen from the loading factor value, shows adequate results. As presented in Table 7, all indicators have a higher correlation or loading factor value for the latent variable than the other variables. Therefore, all measurement models for first-order and second-order have good discriminant validity, convergent validity, and composite reliability.

\begin{tabular}{|l|c|c|c|c|c|c|c|}
\hline & EOU & CN & TM & AC & FM & SE & P value \\
\hline EOU1 & 0.747 & 0.235 & 0.000 & 0.054 & 0.082 & 0.082 & $<0.001$ \\
\hline EOU2 & 0.919 & -0.279 & 0.000 & -0.074 & 0.132 & 0.078 & $<0.001$ \\
\hline EOU3 & 0.907 & 0.139 & 0.000 & -0.191 & 0.014 & 0.078 & $<0.001$ \\
\hline EOU4 & 0.921 & -0.140 & 0.000 & 0.164 & -0.094 & 0.078 & $<0.001$ \\
\hline EOU5 & 0.919 & 0.091 & 0.000 & 0.055 & -0.119 & 0.078 & $<0.001$ \\
\hline CN1 & -0.062 & 0.918 & 0.000 & 0.204 & 0.010 & 0.078 & $<0.001$ \\
\hline & EOU & CN & TM & AC & FM & SE & P value \\
\hline CN2 & 0.067 & 0.878 & 0.000 & -0.260 & 0.155 & 0.079 & $<0.001$ \\
\hline CN3 & -0.002 & 0.887 & 0.000 & 0.046 & -0.164 & 0.079 & $<0.001$ \\
\hline TM1 & -0.062 & 0.787 & 0.918 & 0.204 & 0.010 & 0.078 & $<0.001$ \\
\hline TM2 & 0.067 & 0.914 & 0.878 & -0.260 & 0.155 & 0.079 & $<0.001$ \\
\hline TM3 & -0.002 & 0.986 & 0.887 & 0.046 & -0.164 & 0.079 & $<0.001$ \\
\hline AC1 & 0.150 & 0.158 & 0.000 & 0.923 & -0.208 & 0.078 & $<0.001$ \\
\hline AC2 & -0.077 & 0.108 & 0.000 & 0.921 & 0.100 & 0.078 & $<0.001$ \\
\hline AC3 & -0.099 & -0.361 & 0.000 & 0.680 & 0.148 & 0.083 & $<0.001$ \\
\hline
\end{tabular}




\begin{tabular}{|l|r|r|r|r|r|r|r|}
\hline FM1 & -0.226 & 0.069 & 0.000 & -0.056 & 0.915 & 0.078 & $<0.001$ \\
\hline FM2 & -0.202 & -0.074 & 0.000 & 0.057 & 0.936 & 0.078 & $<0.001$ \\
\hline FM3 & 0.495 & 0.008 & 0.000 & -0.003 & 0.799 & 0.080 & $<0.001$ \\
\hline
\end{tabular}

Table 5. Cross loading first-order

\begin{tabular}{|l|l|l|}
\hline \multicolumn{2}{|l|}{ Indicator/ Variable/items } & 0.730 \\
\hline ERP User Satisfaction (Cronbach Alpha $=\mathbf{0 . 9 2 4 ,} \mathbf{C R}=\mathbf{0 . 9 4 4 ,} \mathbf{A V E}=\mathbf{0 . 7 7 3})$ \\
\hline EOU & Ease of Use & 0.934 \\
\hline CN & Content & 0.934 \\
\hline TM & Timeliness & 0.873 \\
\hline AC & Accuracy & 0.909 \\
\hline FM & Format & \\
\hline Overall Satisfaction (Cronbach Alpha $=\mathbf{0 . 9 5 4 , C R = 0 . 9 6 3 , ~ A V E ~ = ~ 0 . 8 1 3 ) ~}$ \\
\hline US1 & I am satisfied with the convenience provided by ERP cloud. & 0.934 \\
\hline US2 & I am satisfied with the content of ERP cloud. & 0.925 \\
\hline US3 & I am satisfied with the timeliness of information available in ERP cloud. & 0.916 \\
\hline US4 & I am satisfied with the format presented by ERP cloud. & 0.852 \\
\hline US5 & I am satisfied in using ERP cloud & 0.899 \\
\hline US6 & Overall, I am satisfied in using ERP cloud & 0.881 \\
\hline User Job Performance (Cronbach Alpha = 0.948, CR= 0.960, AVE = 0.829) & \\
\hline UJP1 & Using ERP cloud allows me to accomplish tasks faster & 0.912 \\
\hline UJP2 & Using ERP cloud increases my productivity & 0.943 \\
\hline UJP3 & Using ERP cloud improves the performance of my work & 0.930 \\
\hline UJP4 & Using ERP cloud enables me to get more done & 0.869 \\
\hline UJP5 & Using ERP cloud enhances the results of my work & 0.895 \\
\hline
\end{tabular}

Table 6 . Test result for second-order outer model

\begin{tabular}{|l|r|r|r|r|l|}
\hline & \multicolumn{1}{l|}{ EUCS } & \multicolumn{1}{l|}{ OS } & \multicolumn{1}{l|}{ UJP } & \multicolumn{1}{l|}{ SE } & P value \\
\hline EOU & 0.73 & 0.925 & -0.263 & 0.082 & $<0.001$ \\
\hline CN & 0.934 & -0.25 & 0.09 & 0.078 & $<0.001$ \\
\hline TM & 0.934 & -0.25 & 0.09 & 0.078 & $<0.001$ \\
\hline AC & 0.873 & -0.258 & -0.028 & 0.079 & $<0.001$ \\
\hline FM & 0.909 & 0.018 & 0.054 & 0.078 & $<0.001$ \\
\hline US1 & -0.002 & 0.934 & -0.103 & 0.078 & $<0.001$ \\
\hline US2 & -0.073 & 0.925 & 0.052 & 0.078 & $<0.001$ \\
\hline US3 & -0.049 & 0.916 & 0.115 & 0.078 & $<0.001$ \\
\hline
\end{tabular}




\begin{tabular}{|l|r|r|r|r|l|}
\hline US4 & -0.12 & 0.852 & 0.07 & 0.079 & $<0.001$ \\
\hline US5 & 0.02 & 0.899 & -0.159 & 0.078 & $<0.001$ \\
\hline US6 & 0.225 & 0.881 & 0.03 & 0.079 & $<0.001$ \\
\hline UJP1 & 0.043 & 0.235 & 0.912 & 0.078 & $<0.001$ \\
\hline UJP2 & 0.192 & -0.232 & 0.943 & 0.077 & $<0.001$ \\
\hline UJP3 & 0.151 & -0.189 & 0.93 & 0.078 & $<0.001$ \\
\hline UJP4 & -0.369 & 0.156 & 0.869 & 0.079 & $<0.001$ \\
\hline UJP5 & -0.044 & 0.05 & 0.895 & 0.078 & $<0.001$ \\
\hline
\end{tabular}

Table 7. Cross loading second-order

\subsection{Structural Model Evaluation (Inner Model)}

After obtaining validity and reliability results for all constructs, the structural model (Inner Model) was evaluated with second-order latent variables. The data analysis results for the Inner Model were presented in Figure 4. These results show that the $\mathrm{R}^{2}$ value for Overall Satisfaction (OS) and User Job Performance (UJP) is 0.71 and 0.75 , respectively, indicating high explanatory power. The $\mathrm{R}^{2}$ value shows that the various changes in the dependent variable of Overall Satisfaction (OS) are explained by $71 \%$ of the independent variable of satisfaction towards cloud-based ERP (EUCS). The rest is explained by other variables outside the proposed model. Similarly, the User Job Performance (UJP) variable is explained by $75 \%$ of the EUCS and OS variables. Therefore, this study fulfills the $\mathrm{R}^{2}$ criteria.

\subsection{Mediation Testing}

Based on the research model, the effect testing towards individual performance is conducted directly or indirectly through overall satisfaction. The WarpPLS output program results were used to test the mediation effect. The results of the WarpPLS output in Table 8 show that user satisfaction of cloud-based ERP plays a mediating role in individual performance. The mediation's role is indicated by the coefficient, $\mathrm{p}$ value, and effect size on the indirect and total effect tables [23]. As a requirement, all path coefficients should be significant in both model 1 (direct effect) and model 2 (indirect effect) to fulfill the mediation effect. The analysis results in Figure 4 show that all pathways are significant. In model 1, user satisfaction with cloud-based ERP produces a coefficient value of 0.84 and significant at $p<0.01$. Also, in the second model, all pathways produced significant results with a p-value of $<0.01$. Table 8 shows that the indirect effect size is $0.28>0.15$, which indicates a sufficient, as well as the total effect [24].

The next assessment evaluated the effect size value. Practically, the output of the WarpPLS effect size of 0.70 indicates a strong influence of the predictor latent variable $(>0.35)[24]$. 


\begin{tabular}{|c|c|c|c|c|c|c|c|}
\hline \multicolumn{4}{|c|}{ Indirect effects } & \multicolumn{4}{|c|}{$P$ values for total effects } \\
\hline & ES & OS & UJP & & ES & $\mathrm{OS}$ & UJP \\
\hline UJP & 0.333 & & & OS & $<0.001$ & & \\
\hline $\mathrm{p}$ & $<0.001$ & & & UJP & $<0.001$ & $<0.001$ & \\
\hline SE & 0.065 & & & \multicolumn{4}{|c|}{ Standard errors for total effects } \\
\hline Effect Size & 0.28 & & & & ES & $\mathrm{OS}$ & UJP \\
\hline & & & & OS & 0.08 & & \\
\hline & & & & UJP & 0.08 & 0.09 & \\
\hline \multicolumn{4}{|c|}{ Total effects } & \multicolumn{4}{|c|}{ Effect sizes for total effects } \\
\hline & ES & OS & UJP & & ES & $\mathrm{OS}$ & UJP \\
\hline OS & 0.841 & & & OS & 0.707 & & \\
\hline UJP & 0.833 & 0.396 & & UJP & 0.701 & 0.327 & \\
\hline
\end{tabular}

Table 8. Indirect and Total Effects
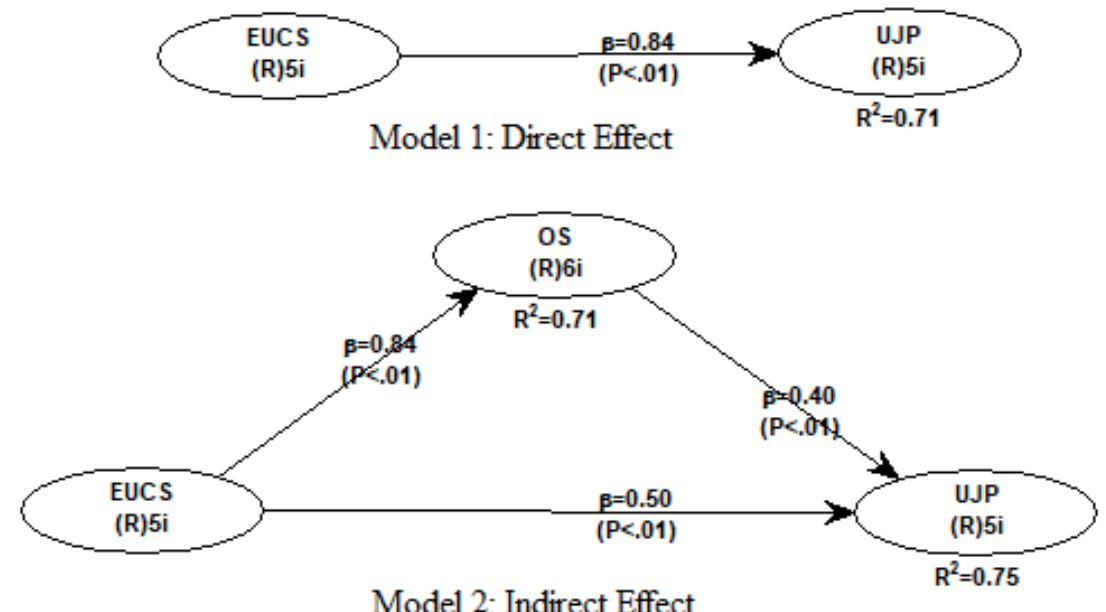

Figure 4. Full Model

\subsection{Testing of Fit Model}

The structural model testing showed a strong relationship between user satisfaction with cloud-based ERP systems and performance. Moreover, there is a mediating effect of ERP satisfaction. The fit model was then tested. Based on the results in Table 9, the model proposed in this study shows an acceptable fit level. The Average Path Coefficient (APC) and Average R-squared (ARS) criteria provide significant value at $\mathrm{p}<0.001$. The Average Full Collinearity VIF (AFVIF) gives a value of 3,381, meaning that the proposed model is fit with the data collected. 
Based on the data in table 9, this research model has fulfilled the goodness of fit criteria. The p-value of APC and ARS, which is less than 0.05, is significant. Therefore, this research model is acceptable.

\begin{tabular}{|l|r|l|}
\hline Index & Value & Result \\
\hline Adjusted R & 0.705 & $>0.7=>$ Strong \\
\hline Average Path Coefficient (APC) & 0.001 & $\mathrm{p}<0.05=>$ Acceptable \\
\hline Average R-Squared (ARS) & 0.001 & $\mathrm{p}<0.05=>$ Acceptable \\
\hline Average Adjusted R-Squared (AARS) & 0.001 & $\mathrm{p}<0.05=>$ Acceptable \\
\hline Average Full Collinearity VIF (AFVIF) & 3.381 & $\mathrm{p}<=5=>$ Acceptable \\
\hline Tenenhaus GoF (GoF) & 0.753 & $>0.36=>$ Large \\
\hline Sympson's Paradox ratio (SPR) & 1 & Ideally \\
\hline R-squared Contribution Ratio (RSCR) & 1 & Ideally \\
\hline Statistical Suppression Ratio (SSR) & 1 & Ideally \\
\hline $\begin{array}{l}\text { Nonlinear Bivariate Causality Direction } \\
\text { Ratio (NLBCDR) }\end{array}$ & 1 & Ideally \\
\hline
\end{tabular}

Table 9. Inner model dan model fit result

The analysis results of the first-order show that all items explain each of the latent variables. These results support the validity and reliability of the EUCS instrument, which was adopted to assess system user satisfaction in a cloud-based ERP system. Therefore, it can be concluded that Hypothesis 1, which states that Ease of Use is a forming element in cloud ERP has empirical support as indicated by the loading factor value of its latent variable which is greater than 0.7 , namely 0.730 . This means that the user satisfaction measurement remains consistent using the ease of use dimension that reflects user-friendliness. The system used can easily provide satisfaction to users, despite showing the smallest value among other dimensions.

Hypothesis 2 which states that Content is a forming element in cloud ERP user satisfaction, that gets empirical support from the loading factor value of its variable by 0.934 . Therefore, it can be concluded that the content presented by a cloud-based ERP system influences user satisfaction, while a high loading factor value indicates a strong explanatory level of satisfaction. Furthermore, the same loading factor value is also found in the Timeliness dimension, by 0.934 , therefore, it can be concluded that Hypothesis 3 which states that Timeliness is a forming element in cloud ERP user satisfaction is supported empirically. This means that timeliness is still an important factor in determining user satisfaction when using cloud-based ERP systems. The test results for Hypothesis 4 which states that Accuracy is a forming element in cloud ERP user satisfaction is accepted by analyzing the loading factor value on the latent variable of 0.873 . The accuracy of the information presented in a cloud-based ERP system contributes to user satisfaction. The last dimension in hypothesis 5, states that the format is a forming element in cloud ERP, with user satisfaction empirically as 
shown by the loading factor value towards the latent variable of 0.909 . The results confirm that these five hypotheses are in accordance with the previous studies in different applications [1], [2], [6], [7]. Therefore, this research adds confirmation of the EUCS validity and reliability in measuring user satisfaction for various computer applications or information technology, which continues to develop and influence the growth of various cloud-based applications.

The next is Hypothesis 6 which states that ERP Cloud User Satisfaction is related to the overall Satisfaction, which also has empirical support as shown on the full model test results in Figure 4. The WarPLS output results indicate a P-value of $<0.1$, which means that the relationship is significant and the hypothesis is empirically accepted. In the same way, the information in Figure 4 also provides empirical support for hypothesis 7 which states that the Overall satisfaction level is related to user performance. These results support the previous studies of [1], [5][22], which mean that individual satisfaction in their interactions with the system has a good impact on their work results. High satisfaction shows that user expectations in completing their work have been fulfilled and adequate in carrying out their tasks.

The dimensions with the greatest contribution to this satisfaction model are content, accuracy, timeliness, and format. The ease of use dimension gets the smallest average value, especially for the operation of the ERP Cloud. These results confirm [6] where ease of use factor needs to be developed for both conventional and cloudbased ERP systems. ERP systems are highly complex and require more effort and time to implement. Therefore, when the ERP becomes implemented, end-users should attend a series of training on how to use it.

Another item with the lowest loading factor value is ERP Cloud that reduces errors in compiling reports. Users perceive cloud ERP systems as not sufficiently reducing errors in compiling reports. It is understood that accountants have a significant role in compiling financial reports sourced from the ERP system. The information is sufficiently available in the ERP system. However, it is not directly used or withdrawn from the system without going through a special process by the accountant. For instance, there is a justification process for certain accounts at the end of the period.

\section{Discussion}

The test results on the structural model confirm previous studies about the validity and reliability consistency of the EUCS instrument. This study has shown that the EUCS instrument remains consistent in measuring user satisfaction for cloud-based ERP systems. The validity and reliability of the instrument are still maintained despite undergoing several modifications. In line with the modifications made on the EUCS instrument by [2]-[4], [6], this study provides the same results regarding the EUCS consistency in measuring user satisfaction in this information age.

The instrument is modified because it adjusts the nature of the computer or internet-based system used. The ease of use, content, timeliness, accuracy, and format dimensions are consistently used to measure end-user satisfaction of an information system or technology. In this research, the ease of use dimensions of a cloud-based 
ERP system has the lowest score. However, this condition is in line with daily practice. Due to the relatively new nature of cloud-based ERP applications [4], endusers should attend a series of training on how to use it. Furthermore, because of the integrated context, cloud-based ERP systems are not used individually with conventional accounting applications. ERP systems require coordination and collaboration with other related departments.

There is a relationship between the end-user satisfaction model proposed in this study, both direct and indirect, with user performance. This relationship has empirical support showing the system's usefulness in daily business processes from the enduser perspective. High satisfaction in using Cloud ERP systems is greatly correlated with increasing individual performance. This study confirms the expansion of general user satisfaction measures. It provides an understanding of the dimensions as the assessment of user satisfaction with cloud-based ERP systems for their daily work. Furthermore, these results confirm previous studies on the relationship between enduser satisfaction and individual performance within the framework of the IS Success model [5], [8], [12], [16]. Therefore, the construct variations of the EUCS and the IS Success Model are examined to show various aspects of the system's success from its users' perspective.

According to [8], individual performance is evidenced by their interaction with the ERP system used in their daily work. Individual performance is measured by the time efficiency to complete quality work. End-users are assisted in obtaining the required information in the decision-making process, and how to identify the potential problems. Application development needs to pay attention to various aspects that affect individual performance improvement. As one of the implications of cloud computing technology development, applications should consider the ease or convenience in using applications in the future. Therefore, it is possible to expand the EUCS instrument.

\section{Conclusion}

This section provides an overall outline of all the research. The first section introduced the research, with various examples on the knowledge gap, work motivation, and research model. The explanation covers the concepts and conditions in the field of information systems using the EUCS model. Previous studies were analyzed using the EUCS model, which motivated the opening of opportunities to confirm and expand the EUCS model on the Cloud-based SaaS ERP system. In addition, the research also examines the relationship between ERP user satisfactions with their performance. Therefore, the first research model explains the confirmation towards the forming factors of EUCS, such as ease of use, content, timeliness, accuracy and format. Secondly, the model explains the relationship between EUCS with Overall user satisfaction and the third analyzes the relationship between Overall user satisfactions with User Job Performance.

The research method in the second part describes all operational variables, data collection methods, and analysis techniques. The first variable used in this study was 
EUCS, which was measured using the concept proposed by Doll and Torkzadeh[20] consisting of 5 dimensions, which were treated as second-order latent variables. Secondly, the overall satisfaction variable is measured using 6 question items, while the last is the performance variable measured by 5 question items. Furthermore, for data processing, this study uses a structural equation model with a partial least square approach to carry out data testing in stages, such as the outer, inner and fit models. The third part is to explain the data processing results descriptively for each variable or analysis of hypothesis testing to examine the relationship between variables. Furthermore, discussions on data processing results are also presented in this section, along with conclusions.

This study confirmed end-user computing satisfaction with cloud-based ERP in the currently developing environment. The system user satisfaction is tested for its relationship with individual performance using the IS Success Model concept. Testing using the second-order latent variable model on the EUCS variable shows that all dimensions consistently form user satisfaction. Almost all dimensions provide high mean values, except for ease of use. These results indicate that end-users do not feel the ease of using cloud-based ERP systems. The low score for the ease of use is due to the complexity of the cloud-based ERP system, which is slightly different from conventional models or other accounting applications. The use of information technology infrastructure that differs from conventional ERP makes end-users initiate various adjustments in its implementation. This research indicates that most users are not familiar with cloud-based ERP systems. However, they give a high enough score for the content, accuracy, timeliness, and format of the cloud-based ERP system.

The expansion of the model revealed a mediating effect of the overall user satisfaction in the relationship between the EUCS satisfaction model and individual performance. The relationship between system end-user satisfaction and individual performance, either directly or indirectly obtained empirical support. These results indicate that the features of a cloud-based ERP system have impacted user performance improvement. A system with appropriate content, timeliness, accuracy, and a format that fulfills user expectations promotes efficiency and effectiveness in performance.

The model's expansion in measuring the overall end-user satisfaction is possible in developing applications, such as cloud computing. The use of IT infrastructure becomes more straightforward in cloud computing because of lower investment costs for companies. Therefore, the implementation cost is lower than conventional ERP because there is no license fee. Therefore, further research should add instruments related to comfort, flexibility, and efficiency to the user satisfaction component. This study focused on the end-user. Therefore, all results obtained are based on the user's experience and perceptions. Future research should extend focus to additional analysis, such as the impact on managerial performance and the company as a whole. Furthermore, task fit and productivity testing need to be prioritized for the satisfaction of end-user information systems. Finally, considering that cloud-based ERP is under the control of the service provider, then its use needs to be extended to the security of the company's internal control system. 


\section{References}

[1] A. Ilias and M. Z. A. Razak, "End-User Computing Satisfaction (EUCS) towards Computerised Accounting System (CAS) in Public," J. Internet Bank. Commer., vol. 16, no. 2, pp. 1-17, 2011.

[2] L. Xiao and S. Dasgupta, "Measurement of user satisfaction with webbased information systems: An empirical study," Proc. Eighth Am. Conf. Inf. Syst. Human-Computer Interact. Stud. MIS, pp. 1149-1155, 2002, doi: 10.1287/isre.3.1.60.

[3] S. F. Abdinnour-Helm, B. S. Chaparro, and S. M. Farmer, "Using the EndUser Computing satisfaction (EUCS) instrument to measure satisfaction with a Web Site," Decis. Sci., vol. 36, no. 2, pp. 341-364, 2005, doi: 10.1111/j.1540-5414.2005.00076.x.

[4] N. Mohamed, H. Hussin, and R. Hussein, "Measuring users' satisfaction with Malaysia's electronic government systems," Electron. J. eGovernment, vol. 7, no. 3, pp. 283-294, 2009, [Online]. Available: http://irep.iium.edu.my/552/.

[5] C. K. Hou, "Examining the effect of user satisfaction on system usage and individual performance with business intelligence systems: An empirical study of Taiwan's electronics industry," Int. J. Inf. Manage., vol. 32, no. 6, pp. 560-573, 2012, doi: 10.1016/j.ijinfomgt.2012.03.001.

[6] T. Somers, K. Nelson, and J. Karimi, "Confirmatory factor analysis of the end-user computing satisfaction instrument: Replication within an ERP domain," Decis. Sci., vol. 34, no. 3, pp. 595-621, 2004, doi: 10.1111/j.1540-5414.2004.02437.x.

[7] V. P. Aggelidis and P. D. Chatzoglou, "Hospital information systems: Measuring end user computing satisfaction (EUCS)," J. Biomed. Inform., vol. 45, no. 3, pp. 566-579, 2012, doi: 10.1016/j.jbi.2012.02.009.

[8] F. Zhong and M. E. Rohde, "Cloud computing and ERP: A framework of promises and challenges," Proc. 25th Australas. Conf. Inf. Syst. ACIS 2014, 2014.

[9] D. Jain and Y. Sharma, "Cloud Computing with ERP - A Push Business Towards Higher Efficiency," SSRN Electron. J., vol. 4, no. March, pp. 140-155, 2017, doi: 10.2139/ssrn.2755457.

[10] P. Hanafzadeh, R. Gholami, S. Dadbin, and N. Standage, "The core critical success factors in Implementation of Enterprise Resource Planning systems," Int. J. Enterp. Inf. Syst., vol. 6, no. 2, pp. 82-111, 2010, doi: 10.4018/jeis.2010040105.

[11] A. Shatat, "Critical success factors in enterprise resource planning system implementation: An analysis," ProQuest Diss. Theses, vol. 18, no. 1, p. 
139, 2010, [Online]. Available:

https://search.proquest.com/docview/759240980?accountid=15297\%5Cnht tp://bs8lz6ys5q.search.serialssolutions.com/?ctx_ver=Z39.88-

2004\&ctx_enc=info:ofi/enc:UTF-

8\&rfr_id=info:sid/ABI\%2FINFORM+Global\&rft_val_fmt=info:ofi/fmt:ke $\mathrm{v}: \mathrm{mtx}$ :dissertation\&rft.genre $=$ diss.

[12] K. S. Wei, A. C. Y. Loong, Y.-M. Leong, and K.-B. Ooi, "Measuring ERP System Success: A Respecification of the Delone and McLean's IS Success Model," Symp. Prog. Inf. Commun. Technol. 2009, pp. 7-12, 2009, [Online]. Available: http://spict.utar.edu.my/SPICT09CD/contents/pdf/SPICT09_A1_2.pdf\%5Cnhttp://130.203.133.150/viewdoc/summary?doi=10.1.1.160.50 14 .

[13] A. D'Souza, "ERP Software Market to Reach a Market Size of $\$ 70.3$ Billion by 2025," KBV Research, 2019.

https://www.prnewswire.com/news-releases/erp-software-market-to-reacha-market-size-of-70-3-billion-by-2025--kbv-research-300966731.html (accessed Mar. 31, 2020).

[14] G. E. Heilman, J. Brusa, and A. Texas, "Validating the End User," pp. 84 96, 2006.

[15] Oracle, "Emerging Technologies : Driving Financial and Operational Efficiency," 2020.

[16] W. A. Cidral, T. Oliveira, M. Di Felice, and M. Aparicio, "E-learning success determinants: Brazilian empirical study," Comput. Educ., vol. 122, pp. 273-290, 2018, doi: 10.1016/j.compedu.2017.12.001.

[17] G. Norfazlina, A. S. S. Akma, S. N. Adrina, and M. M. Noorizan, "Customer Information System Satisfaction and Task Productivity: The Moderating Effect of Training," Procedia Econ. Financ., vol. 37, no. 16, pp. 7-12, 2016, doi: 10.1016/s2212-5671(16)30085-5.

[18] D. Stefanovic, U. Marjanovic, M. Delić, D. Culibrk, and B. Lalic, "Assessing the success of e-government systems: An employee perspective," Inf. Manag., vol. 53, no. 6, pp. 717-726, 2016, doi: 10.1016/j.im.2016.02.007.

[19] C. Tam and T. Oliveira, "Understanding the impact of m-banking on individual performance: DeLone \& McLean and TTF perspective," Comput. Human Behav., vol. 61, pp. 233-244, 2016, doi: 10.1016/j.chb.2016.03.016.

[20] W. J. Doll and G. Torkzadeh, "The Measurement of End-User Computing Satisfaction End-User Satisfaction The Measurement of End-User Computing Satisfaction Professor of MIS and Strategic Management The 
University of Toledo Gholamreza Torkzadeh Assistant Professor of Information Systems," MIS Q., vol. 12, no. 2, pp. 259-274, 1988, [Online]. Available:

http://www.jstor.org/stable/248851\%0Ahttp://www.jstor.org/page/info/abo ut/policies/terms.jsp\%0Ahttp://www.jstor.org.

[21] G. M. Ling, Y. S. Fern, L. K. Boon, and T. S. Huat, "Understanding Customer Satisfaction of Internet Banking: A Case Study In Malacca," Procedia Econ. Financ., vol. 37, no. 16, pp. 80-85, 2016, doi: 10.1016/s2212-5671(16)30096-X.

[22] W. H. DeLone and E. R. McLean, Information Systems Success Measurement, vol. 2, no. 1. 2016.

[23] N. Kock, “WarpPLS 7.0 user manual,” 2020.

[24] N. Kock, "Advanced Mediating Effects Tests, Multi-Group Analyses, and Measurement Model Assessments in PLS-Based SEM," Int. J. eCollaboration, vol. 10, no. 1, pp. 1-13, 2014, doi:

10.4018/ijec.2014010101. 